www.jmscr.igmpublication.org Impact Factor 5.244

Index Copernicus Value: 83.27 ISSN (e)-2347-176x ISSN (p) 2455-0450 crossref DOI: https://dx.doi.org/10.18535/jmscr/v5i1.10

\title{
Skin Sparing Mastectomy with Immediate Breast Reconstruction by Augmentation Flap in Early Breast Cancer
}

\author{
Authors \\ Nasir U Din Wani ${ }^{1}$, Shabir Iqbal ${ }^{2}$, Khursheed Alam ${ }^{3}$, Ajaz Malik $^{4}$, Adil Hafiz ${ }^{5}$ \\ ${ }^{2,5}$ Department of Plastic \& Reconstructive Surgery, Sher-i-Kashmir Institute of Medical Sciences, Soura, \\ Srinagar -190011, J \& K, India \\ ${ }^{3,4}$ Department of General Surgery, Sher-i-Kashmir Institute of Medical Sciences, Soura, Srinagar -190011, \\ $\mathrm{J} \& \mathrm{~K}$, India \\ Corresponding Author \\ Dr. Nasir-ud-din Wani \\ Medical Officer, Government Medical College, Srinagar, Kashmir \\ Email: drnasir629@gmail.com, Phoneno.9419053008
}

\begin{abstract}
.
Skin sparing mastectomy (SSM) refers to the maximum preservation of patients own skin with the removal of only nipple-areola complex and any breast skin involved with or close to the tumor. The aim of the study was to analyze the applicability of SSM with IBR, comparison of breast conserving surgery without reconstruction and SSM with IBR in terms of patient satisfaction, psychological impact and local recurrence rate, and follow up of patients in prospective group to look for cosmesis, breast mound, breast skin color and flap necrosis. 20 patients of early breast cancer in prospective group were subjected to SSM and IBR and compared with all the patients of early breast cancer who were admitted in the Department of General Surgery for breast conserving surgery. The mean age in the prospective group was 43.7 years with a mean hospital stay of 4.8 days. Most (60\%) of the patients were in stage II. 95\% of the patients were having duct cell carcinoma on FNAC. In the prospective group, all the patients were subjected to SSM and IBR by Latissimus dorsi myocutaneous flap followed by post-operative chemotherapy and radiotherapy. In prospective group, none of the patients had local recurrence, $90 \%$ of the patient had positive psychological impact, $85 \%$ of the patients had good satisfaction and $75 \%$ of the patients had good post-reconstruction cosmesis. It was concluded that SSM is oncologically safe and SSM and IBR are appropriate treatment for patients with early breast cancer; the use of SSM has improved breast reconstruction outcomes and has thereby enhanced the quality of life of our patients.

Keywords: Skin sparing mastectomy; breast reconstruction; early breast carcinoma, latissimus dorsi flap; flap necrosis; cosmesis.
\end{abstract}

\section{Introduction}

Carcinoma of the breast is a major and important form of malignant disease all over the world. India also faces a potential breast cancer epidemic over the next decade. Currently, India reports 100,000 new cases annually. Studies indicate that as India becomes westernized, the incidence rate for breast cancer will increase. A 2005 study conducted by 
the International Association of Cancer Research, based in Lyon, France, projected that there would be 250,000 cases of breast cancer in India by 2015, a 3\% increase per year. ${ }^{1}$

The management of breast cancer has passed through various stages of evolution from extensive procedures such as Halsted's radical mastectomy or modified radical mastectomy to breast conserving treatments. With regards to breast skin sacrifice, Halsted's technique removes all the breast skin, while modified radical mastectomy resects only segments of breast skin on either side of nipple-areola complex. Since breast carcinoma is a malignant proliferation of epithelial cell lining of the duct or lobules of breast, it is not necessary to discard the breast skin unless it is actually involved with the disease. ${ }^{2}$

Skin sparing mastectomy (SSM) refers to the maximum preservation of patients own skin with the removal of only nipple- areola complex and any breast skin involved with or close to the tumor. As the breast skin and crease are preserved there is little to reconstruct (only the missing breast gland and nipple- areola complex) allowing a more natural result. The SSM is otherwise a standard modified radical mastectomy which entails removal of all breast tissue and level I \& II axillary dissection. ${ }^{3,4}$

The study was aimed at 1) To analyze the applicability of Skin sparing mastectomy (SSM) with immediate breast reconstruction (IBR), 2) Comparison of breast conserving surgery without reconstruction and SSM with IBR in terms of patient satisfaction, psychological impact and local recurrence rate, and 3) follow up of patients in prospective group to look for cosmesis, breast mound, breast skin color and flap necrosis.

\section{Material \& Methods}

The study was conducted at Sher-i-Kashmir Institute of Medical Sciences in Departments of General Surgery and Plastic and Reconstructive Surgery. A total of 28 cases were included in the study- 20 patients in the prospective group while 8 cases managed by breast conservation surgery were taken retrospectively for comparison of two methods of surgical management viz skin sparing mastectomy and immediate reconstruction by augmentation flap and breast conservation surgery (BCS). Inclusion criteria were set to include only the patients with stage I and II breast cancer. A detailed local examination was carried out on all the patients. Local examination included the details of primary lesion, any lymph node metastasis, anatomical location of tumor in the breast, status of the opposite breast and the site of donor flap.

\section{Surgery}

All the patients in the prospective group were subjected to skin sparing mastectomy and immediate reconstruction by L.D. myocutaneous flap. In most of the cases a periareolar incision was made but in some cases this incision was extended transversely to facilitate mastectomy. In a few cases, periareolar incision was extended to include the FNAC site. Axillary clearance was done in all cases via the periareolar incision after completion of mastectomy. Level I, II and III axillary nodes were removed in all cases along with axillary fat with skeletonization of the axillary vein. Rotter's nodes were removed only when enlarged. Tissue specimen was taken from the breast skin flap after mastectomy to confirm that no breast tissue was left. After completion of skin sparing mastectomy, patients were changed from supine to lateral side to facilitate L.D. flap dissection. Then an elliptical incision was made over L.D. site extending from the posterior axillary fold up to the iliac crest. In most of the patients, the skin coming under the elliptical incision was de-epithelized to add bulk to the flap. This is the modification of simple L.D. flap called extended L.D. flap. The L.D. muscle with overlying subcutaneous tissue was meticulously raised based on thorocodorsal artery. Then a subcutaneous tunnel was made joining the L.D. flap site and the mastectomy site. Then whole of the myocutaneous flap was transferred to the mastectomy site through this tunnel, making sure 
that there is no twist or tension on the vascular pedicle. Myocutaneous flap at mastectomy site was then moulded into the shape of the breast and fixed with the breast skin by 2 to 3 sutures. Whole of the resected specimen was sent for histopathological examination.

\section{Adjuvant systemic chemotherapy and radiotherapy}

All patients were subjected to post operative chemotherapy and radiotherapy. Post operative mammography was done in all patients in prospective group at 6 monthly intervals to look for any local recurrence.

\section{Follow-up}

The patients were followed up weekly for one month, monthly for 6 months and 3 monthly thereafter. Patients in prospective and retrospective group were compared for:

a) Patient satisfaction.

b) Psychological impact.

The psychological effects of the procedure were evaluated with the help of a questionnaire containing ten statements (Table 1). Each question was allotted " 1 " score for a "Yes" and " 0 " score for a No. A score of "6" or more was considered an overall "positive" effect.

c) Any local recurrence.

All the patients in the prospective group were assessed in there follow up for:

1. Breast cosmesis- WINCHISTER \& COX scoring system. (Table 2)

2. Breast mound.

3. Any change in breast skin color.

4. Flap necrosis.

5. Any other complication.

\section{Results}

28 patients were included in the study. They were aged between 22-56 years with a mean age of 43.7 years in the prospective group and 47 years in the retrospective group. The most common site involved in both the groups was upper and outer quadrant and least common site involved was upper and inner quadrant. About $60 \%$ of the patients had T1N1M0 status. Rest of the patients had T1N0M0 and T2N1M0 status. All patients had invasive ductal carcinoma except one patient in the prospective group who had invasive lobular carcinoma. Two patients in the prospective group were given pre-operative chemotherapy.

Axillary clearance was done in all the patients in the prospective group but in none of the patients in retrospective group. Post-operative radiotherapy was given to all the patients in both the groups. While post-operative chemotherapy was given to all the patients in prospective group, only $6(75 \%)$ patients in the retrospective group received post-operative chemotherapy.

Out of 20 patients in prospective group, 6 patients (30\%) had complications. 5 patients $(25 \%)$ had seroma at L.D. site and 1 patient (5\%) had wound gaping at mastectomy site. The difference was not statistically significant when compared with the retrospective group. However a statistically significant ( $p$ 0.023) association was found in local recurrence rates and the type of surgery. Local recurrence was seen in $25 \%$ of patients in retrospective group and none of the patients in prospective group. The patients in retrospective group who developed recurrence were those who did not receive post-operative chemotherapy.

Post-operative psychological impact was positive in $90 \%$ of patients in prospective group, whereas it was positive in only $25 \%$ of the patients in retrospective group. The psychological impact was positive in higher percentage of patients in prospective group because these patients were both oncologically safe and cosmetically good. The difference was found to be statistically significant (p 0.007). Seventeen (85\%) patients in the prospective group and $2(25 \%)$ in the retrospective group were satisfied with the surgical procedure. The results when compared were statistically significant. (p 0.013). 
In our study, out of 20 patients 15 patients $(75 \%)$ had good cosmesis, 4 patients (20\%) had fair cosmesis and 1 patient $(5 \%)$ had poor cosmesis.

Table 1: Questionnaire to assess psychological effects of the procedure.

\begin{tabular}{|l|c|c|}
\hline Statements & \multicolumn{2}{|c|}{ Scores } \\
\hline Feel whole. & Yes (1) & No (0) \\
\hline Feel normal. & Yes (1) & No (0) \\
\hline Feel balanced / Symmetrical. & Yes (1) & No (0) \\
\hline Feel feminine. & Yes (1) & No (0) \\
\hline Satisfied with appearance. & Yes (1) & No (0) \\
\hline Can wear all types of clothes. & Yes (1) & No (0) \\
\hline Positive psychological effect. & Yes (1) & No (0) \\
\hline Normal social interaction. & Yes (1) & No (0) \\
\hline $\begin{array}{l}\text { Satisfied with feel of reconstructed } \\
\text { breast. }\end{array}$ & Yes (1) & No (0) \\
\hline Decreased thoughts of cancer. & Yes (1) & No (0) \\
\hline $\begin{array}{l}\text { Overall psychological effect. } \\
\text { Positive if }=/>\mathbf{6}\end{array}$ & \multicolumn{2}{|l}{} \\
\hline
\end{tabular}

Table 2:-Winchester \& Cox scoring system for post-reconstruction cosmesis.

\begin{tabular}{|l|c|}
\hline Findings (Winchester \& Cox). & Cosmesis \\
\hline $\begin{array}{l}\text { Treated breast almost identical to untreated } \\
\text { breast. }\end{array}$ & Excellent. \\
\hline $\begin{array}{l}\text { Minimal difference between treated and } \\
\text { untreated breast. }\end{array}$ & Good. \\
\hline $\begin{array}{l}\text { Obvious difference between treated and } \\
\text { untreated breast. }\end{array}$ & Fair. \\
\hline $\begin{array}{l}\text { Major functional and esthetic sequelae in } \\
\text { treated breast. }\end{array}$ & Poor. \\
\hline
\end{tabular}

\section{Discussion}

Skin sparing mastectomy (SSM) has afforded plastic surgeons an unparalled opportunity to reconstruct a life-like breast ensuring simultaneously complete removal of tumor like tissue. ${ }^{5,6,7}$ The indications of skin sparing mastectomy are 1). Multicentricity of disease (ductal carcinoma in situ). 2). Invasive carcinoma associated with an extensive intraductal component that is $25 \%$ or more of the tumor volume. 3). T2 tumors (2 to 5 $\mathrm{cm}$ ), especially those with unfavorable features on radiographic or physical examination that defy confidence in follow up examination. 4). A central tumor that would require removal of nipple areola complex. $^{8-11}$

Additional patients have been selected for limited skin resection because of relatively favorable indications, and include the following- In situ cancers of ductal and lobular origin, multifocal, minimal breast cancer (Tmic, T1a, T1b), all T1 and possibly T2a tumors deep within the breast parenchyma, following neoadjuvant therapy, with significant reduction of tumor volume. Indications for skin sparing mastectomy and immediate breast reconstruction have continued to broaden and recent studies report the technique being used even for advanced stages of breast carcinoma. $^{12,13,14}$

In this series only well motivated patients with early breast disease without involvement of skin and underlying muscles were included. These strict criteria were adopted so as to minimize perioperative morbidity and achieve optimal results for the different techniques employed. Reconstruction was done using a Latissimus Dorsi (LD) myocutaneous flap. Immediate reconstruction can be done using either TRAM or LD flap. The Latissimus Dorsi flap is one of the first flaps used in breast reconstruction. ${ }^{15,16}$ It lost its popularity with the use of TRAM flap which provided much more breast like tissue (fat) and avoided an implant. ${ }^{17,18}$ However the Latissimus Dorsi flap is experiencing a renaissance because of its vascular reliability and avoidance of the abdominal herniation potential seen with the use of TRAM flap. ${ }^{19-22}$

In the present study, the two groups were comparable in terms of age, side of breast involved, location of lesion and duration of symptoms. Most of our patients in the both the prospective as well as retrospective group were having stage II disease. However none of the patients in retrospective group were in stage IIB. Ho et al. $^{23}$ found that the frequency of skin involvement in $\mathrm{T} 1$ and $\mathrm{T} 2$ lesions was very small $(3 \%)$. They suggested that the nipple-areola complex could be preserved in axillary node negative patients with small (T1 or T2), solitary tumors located peripherally. We, however, removed the nipple-areola complex in our SSMs to reduce the possibility of local recurrence.

$10 \%$ of our patients in the prospective group were subjected to neoadjuvant chemotherapy to 
improve the long term survival. Mauriac and colleagues $^{24}$ reported a series of 272 patients with operable breast tumors more than $3 \mathrm{~cm}$ in diameter. In this randomized trial, patients received either mastectomy followed by adjuvant chemotherapy or neoadjuvant chemotherapy followed by loco-regional treatment. The neoadjuvant chemotherapy group had longer overall survival, with a median follow up of 34 months.

We subjected all of our patients in prospective group to axillary dissection because loco-regional recurrence is less in patients in whom axillary dissection has been done. ${ }^{25,26}$ Each patient in prospective group was subjected to post-operative chemotherapy to reduce the possibility of local and distant recurrence. According to National Institute of Health Centre Consensus Development Panel, ${ }^{27}$ adjuvant chemotherapy or hormone therapy is routinely recommended for most patients with tumor more than $1 \mathrm{~cm}$, removing knowledge of nodal status from the decision-making process. In our study, local recurrence was seen in $25 \%$ of patients in retrospective group, while none of the patients in prospective group had recurrence. The patients in retrospective group who developed recurrence were those who did not receive post-operative chemotherapy. This difference was statistically significant. In recent studies, local recurrence rates after skin sparing mastectomy and immediate breast reconstruction have varied between 0 and $7.9 \%$, whereas total recurrence rates (including systemic recurrence) may reach $20 \%$, depending on patient selection and length of follow-up ${ }^{28,29 .}$ All the patients were subjected to post-operative radiotherapy as well to prolong the disease free survival as has been suggested by Ragaz et al. and Early Breast Cancer Trialist's Group. $^{30}$

Since 1952, when Renneker and Culter ${ }^{31}$ first described the dual emotional trauma of mastectomy (psychological reactions of both the breast loss and the diagnosis of cancer), it has been found that immediate reconstruction eliminates the psychological reactions of despair, depression, decreased self-esteem, diminished sexuality and loss of feeling of femininity related due to the loss of breast. This was found to be statistically significant in our study where postoperative psychological impact was positive in $90 \%$ of patients in prospective group against $75 \%$ of patients in retrospective group.

In our study, the patients in prospective group were assessed for post-reconstruction cosmesis according to Winchester and Cox scoring system. Out of 20 patients in prospective group, 15 (75\%) patients had good cosmesis. Mamoon Rashid et al. $^{32}$ in their study of skin sparing mastectomy and immediate breast reconstruction had excellent aesthetic restoration in $82 \%$ of patients, good restoration in $3.5 \%$ of patients and fair in $14 \%$ of patients. Excellent restoration actually depends on the reconstruction of nipple-areola complex. However in our study patients were reluctant for nipple-areola reconstruction because they didn't want to undergo one more surgery.

Surgical complications of skin sparing mastectomy have been reviewed in previous studies. Skin flap complications remain the special concern as they are specific to this operation and may threaten the success of the breast reconstruction. The skin flap complication rates described by Slavin \& colleagues $(21.6 \%)^{33}$ and Carlson and co-workers $(10.7 \%)$ were comparable with those in the present study (5\%). Other complications in our study were the post-operative seroma at Latissimus Dorsi site seen in 2 patients $(10 \%)$. All these patients were treated with needle aspiration followed by application of crepe bandage. Although immediate breast reconstruction is known to increase the risk of postoperative hematoma compared with simple mastectomy, this study showed the procedure to be surgically safe.

This study suggest that the use of skin sparing mastectomy is oncologically safe and provides support for those who believe that skin sparing mastectomy and immediate reconstruction are appropriate treatment for patients with early breast 
cancer who must undergo mastectomy. We believe that the use of skin sparing mastectomy has improved our breast reconstruction outcomes and has thereby enhanced the quality of life of our patients. To conclude, the use of skin sparing mastectomy (SSM) in conjunction with immediate breast reconstruction (IBR) is a team effort - one that requires close cooperation between the general surgeons and plastic surgeons.

\section{Sources of support in the form of grants: nil}

\section{Bibliography}

1. Sanjit Bagchi. Breast cancer rises in India. CMAJ. 2008.

2. Millard DR Jr. Principlization of Plastic Surgery. Little, Brown, Boston, 1986.

3. Toth BA, Lappert P. Modified skin incisions for mastectomy: the need for plastic surgical input in pre-operative planning. Plast Reconstr Surg.1991; 87: 1048.

4. Singletary SE. Skin sparing mastectomy and immediate breast reconstruction. Med Gen Med.1999; 1(1) [Formally published in Medscape Women's Health Journal. 1996;1(5).

5. Veronesi U, Banfi A, Salvadori B. Breast conservation is the treatment of choice in small breast cancer: long term results of a randomized trial. Eur J Cancer 1990; 26: 668.

6. Schain Ws, Wellisch DK, Pasnau RO, et al. The sooner the better: a study of psychological factors in women undergoing immediate versus delayed breast reconstruction. Am J Psychiatry 1985; 142: 40.

7. Noone RB, Frazier TG, Hayward CZ, et al. Patient's acceptance of immediate reconstruction following mastectomy. Plast Reconstr Surg 1982; 69: 632.

8. Carlson GW. Skin sparing mastectomy: anatomic and technical considerations. Am Surg.1996; 62: 151.
9. Sampaio Goes J. Mastectomy by periareolar approach with immediate breast reconstruction. Rev Loc Bras Cir Estet Reconstr.1995; 10: 44.

10. D. Lehman, M.D.,Ph.d., et al. MRI evaluation of the contralateral breast in women with recently diagnosed breast cancer. The New Engl J Med.2007;356:13..

11. Renato Z T, Cesar C S, Henrique Brenelli et al. Residual glandular tissue after skin sparing mastectomies. The Breast Journal, Volume 11, number 5, 2005:374-375.

12. Newman LA, Kuerer HM, Hunt KK, et al. Feasibility of immediate breast reconstruction for locally advanced breast cancer. Ann surg oncol 1999; 6: 671-675.

13. Foster RD, Esserman LJ, Anthony JP, et al. Skin-sparing mastectomy and immediate breast reconstruction: a prospective cohort study for the treatment of advanced stages of breast carcinoma. Ann surg oncol 2002; 9: 462-466.

14. Downes KJ, Glatt BS, Kanchwala SK, et al. Skin-sparing mastectomy and immediate breast reconstruction is an acceptable treatment option for patients with high risk breast carcinoma. Cancer 2005; 103: 906913.

15. Schneider W, Hill L, Brown GR. Latissimus Dorsi myo-cutaneous flap for breast reconstruction. Br J Plast Surg. 1977; 30:277.

16. Bostwick J III, Scheflan M. the Latissimus Dorsi myo-cutaneous flap; A one stage breast reconstruction. Clin Plast Surg. 1980; 7:71.

17. Hartrampf CR Jr., Scheflan, Black PW. Breast reconstruction following mastectomy with a transverse abdominal island flap. Anatomical and clinical observations. Plast. Reconstr. Surg. 1982; 69:216.

18. Hartrampf CR (ed). Breast reconstruction with living tissue, New York, Raven Press, 1990. 
19. Hartrampf CR Jr. abdominal wall competence in transverse abdominal island flap operations. Ann Plast Surg.1984; 12:139.

20. Lejour M, Dome. Abdominal wall function after rectus abdominis transfer. Plast reconstr Surg. 1991; 87:1054.

21. Kroll SS, Marchi M. Comparison of strategies for preventing abdominal wall weakness after TRAM flap breast reconstruction. Plast Reconstr Surg.1991; 89:1045.

22. Mizgala CL, Hartrampf CR Jr. Bennet GK. Abdominal function after pedicled TRAM flap surgery. Clin Plast Surg.1994; 21(2):255.

23. Ho CM, Mak Ck, Lau Y, et al. Skin involvement in invasive breast carcinoma: safety of skin-sparing mastectomy. Ann Surg Oncol 2003; 10: 102-107.

24. Mauriac L. et al: Effects of primary chemotherapy in conservative treatment of breast cancer patients with operable tumors more than $3 \mathrm{~cm}$ : results of a randomized trial in a single centre, Ann Oncol 1991: 2; 347.

25. Hagenson CD: Disease of breast, ed 2, Philadelphia, 1971.

26. Fisher B et al. Ten year results of a randomized clinical trial comparing radical mastectomy and total mastectomy with or without radiation, N Engl J Med 1985: $312 ; 674$.

27. National Institute of Health Centre Consensus development panel: Adjuvant therapy for breast cancer, Nov 1-3, 2000, J Natl Cancer Inst 2001: 93; 979.

28. Carlson GW, Sttyblo TM, Lyles RH, et al. Local recurrence after skin-sparing mastectomy: tumor biology or surgical conservatism? Ann surg oncol 2003; 10: 108- 112.

29. Medina-Franco H, Vasconez LO, Fix RJ, et al. Factors associated with local recurrence after skin-sparing mastectomy and immediate breast reconstruction for invasive breast cancer. Ann surg 2002; 235: 814-819.

30. Early Breast Cancer Trialist Group: Favorable and unfavorable effects on longterm survival of radiotherapy for early breast cancer: an overview of the randomized trials, Lancet 2000: 355; 1757.

31. Renneker, R., and Culter, M. Psychological problems of adjustment to cancer of the breast. J.A.M.A.1952;148:833.

32. Mamoon Rashid, Irfan Ilahi, et al. Skin sparing mastectomy and immediate breast reconstruction. JCPSP 2005, vol. 15 (8):467-471.

33. Slavin SA, Schnitt SJ, Duda RB, et al. Skin-sparing mastectomy and immediate reconstruction; oncologic risks and aesthetic results in patients with early stage breast cancer. Plast Reconstr Surg $1998 ; 102 ; 49-62$. 